problems of an injury to the hand with greater confidence and the comprehensive index permits rapid revision of any point.

\section{Neurological Examination in Clinical Practice}

By Edwin R. Bickerstaff. Second edition. Pp. 378, illustrated. Oxford and Edinburgh: Blackwell Scientific Publications, 1968. 63s.

This is the second edition of Dr Bickerstaff's book in which he has extended several sections to bring them up to date and has added chapters on the more modern neurological investigations including cerebral scanning and echo-encephalography.

Although this book has many rivals, there are few as comprehensive and, at the same time, as free from verbosity. It is clearly written and gives a precise account of the examination of the nervous system, simply stated and profusely illustrated. The section on the examination of the cranial nerves is especially good with a helpful note on the difficulties and fallacies commonly encountered. The chapters on examinations of particular difficulty, especially those on small children and on laboratory investigations, are equally well done. The concuding section in which the author gives his indications for the investigation of certain common neurological disorders is excellent.

This is an outstanding book and is to be strongly recommended.

\section{Disease in Infancy and Childhood}

By R. W. B. Ellis and R. G. Mitchell. Sixth edition. Pp. 687, illustrated. Edinburgh and London: E. \& S. Livingstone, 1968. 80s.

If there are no perfect textbooks there are a few that approach the ideal, though with the increasing tempo of change in medicine they are becoming rarer. The good traditional book was meant to keep: the modern one is meant to be replaced. The good textbook read well, and should still do so even in our four-letter word era. It was more than a bare repository of data: it meant and should still mean something in the lives of its readers. Its single authorship gave a uniformity of style and philosophy which has become uncommon now that even small books remind one of multistorey car parks.

The many virtules of 'Ellis' are maintained in the sixth edition. Professor Mitchell has renovated it admirably, and contributes much that is new while cherishing its individuality and character. It remains pleasant to handle and to read. Its approach has always been stimulatingly different from most paediatric texts. The common description of disease by systems is often illogical when applied to childhood; here we can enjoy the attempt to adapt it to age-periods and the changing reaction of the immature host. There is no falling into the trap, irresistible to the authors of so many small texts, of futilely mentioning as many rare diseases as can be squeezed into a line or two. It starts with a description of social and environmental factors which gives depth to all the rest. The synthesis in the chapters on congenital malformations, neoplasms, disorders of storage and metabolism is among the most successful. In the non-physical aspects of childhood disorders it is neither so ambitious nor so successful, and the chapter on behavioural disorders, at present sketchy, should be brought up to the level of the rest.

I know of no small paediatric book at this time which gives anything like the perspective of this one. It is intended for senior medical students, but will be just as pleasurable and useful for graduates, including non-paediatricians, who know where to go for greater detail but wish to get the tang and broad sweep of modern paediatrics. 